\title{
Mechanical Thrombectomy Using the New ERIC Retrieval Device Is Feasible, Efficient, and Safe in Acute Ischemic Stroke: A Swiss Stroke Center Experience
}

\author{
T. Kahles, C. Garcia-Esperon, S. Zeller, M. Hlavica, J. Añon, M. Diepers, K. Nedeltchev, and L. Remonda
}

\begin{abstract}
BACKGROUND AND PURPOSE: Intravenous thrombolysis and mechanical thrombectomy predominantly using stent retrievers have been shown to effectively restore cerebral blood flow and improve functional outcome in patients with acute ischemic stroke. We sought to determine the safety and feasibility of mechanical thrombectomy using the new ERIC retrieval device.
\end{abstract}

MATERIALS AND METHODS: We identified 36 consecutive patients from our Stroke Center registry with acute ischemic stroke who were treated with the new ERIC retriever from September 2013 to December 2014. Patients with ischemic stroke meeting the following criteria were eligible: onset-to-treatment time of $\leq 4.5$ hours or wake-up stroke $(n=10)$ with relevant CT perfusion mismatch, NIHSS score of $\geq 4$, and proof of large-vessel occlusion in the anterior circulation on CT angiography. We assessed the baseline characteristics including age, sex, comorbidities, stroke severity, site of vessel occlusion, presence of tissue at risk, and treatment-related parameters such as onsetto-treatment time, recanalization grade, and outcome.

RESULTS: The mean age was $70 \pm 13$ years, and the median NIHSS score on admission was 18 (interquartile range, 10-20). Seventeen of 36 patients were on platelet inhibitors or anticoagulants before endovascular treatment (47.2\%); 20 patients received intravenous thrombolysis (55.5\%). The ERIC was used as the sole retriever in 28 patients (77.8\%) and as a rescue device in 8 . Excellent recanalization was achieved in 30/36 patients (83.3\%) with $\mathrm{TICl} 3$ in 19/36 and 2b in 11/36, respectively. Median procedural time in these patients was 90 minutes (interquartile range, 58-133 minutes). No intraprocedural complications occurred.

CONCLUSIONS: In this observational study, the new ERIC retrieval device was technically feasible, safe, and effective in acute ischemic stroke with large-vessel occlusion.

ABBREVIATIONS: ERIC = Embolus Retriever with Interlinked Cages; IQR = interquartile range; IVT = intravenous thrombolysis; sICH = symptomatic intracerebral hemorrhage

$\mathbf{E}_{\mathrm{ata}}^{\mathrm{an}}$ arly restoration of cerebral blood flow is crucial to prevent persistent brain damage in acute ischemic stroke. Intravenous thrombolysis (IVT) with tPA has been shown to increase recanalization rates ${ }^{1}$ and improve clinical outcome within 4.5 hours after symptom onset. ${ }^{2,3}$ Still, its effectiveness in large-vessel occlusion is rather limited. ${ }^{4}$ In contrast, endovascular interventions, in particular mechanical thrombectomy, have revealed high rates of recanalization in proximal artery occlusion (reviewed by Jansen and $\operatorname{Rohr}^{5}$ ). In the past decade, various devices have been introduced for this purpose (reviewed by Spiotta et $\mathrm{al}^{6}$ ). Just recently,

Received March 10, 2015; accepted after revision May 15.

From the Departments of Neurology (T.K., C.G.-E., S.Z., K.N.) and Neuroradiology (M.H, J.A., M.D., L.R.), Cantonal Hospital Aarau, Aarau, Switzerland.

Please address correspondence to Luca Remonda, MD, Department of Neuroradiology, Cantonal Hospital Aarau, Tellstr, CH- 5001 Aarau, Switzerland; e-mail: luca.remonda@ksa.ch

三 Indicates article with supplemental on-line tables.

http://dx.doi.org/10.3174/ajnr.A4463 new-generation stent retrievers were launched and proved to be even more effective than previous approaches. ${ }^{7-9}$

However, even the latest devices need to be deployed for several minutes before retrieving the thrombus and thus require precious time. Moreover, 1 device does not fit all occlusion types, and alternative effective devices are warranted. In this pilot study, we sought to determine the feasibility, efficacy, and safety of mechanical thrombectomy in patients with acute ischemic stroke by using the new Embolus Retriever with Interlinked Cages (ERIC; MicroVention, Tustin, California) (Fig 1B).

\section{MATERIALS AND METHODS \\ Patients}

We identified 36 consecutive patients with acute stroke who were treated with the new ERIC device from September 2013 to December 2014 at the Cantonal Hospital Aarau Stroke Center. Ethical approval was obtained from the local ethics committee.

Patients with ischemic stroke were eligible if they met the fol- 

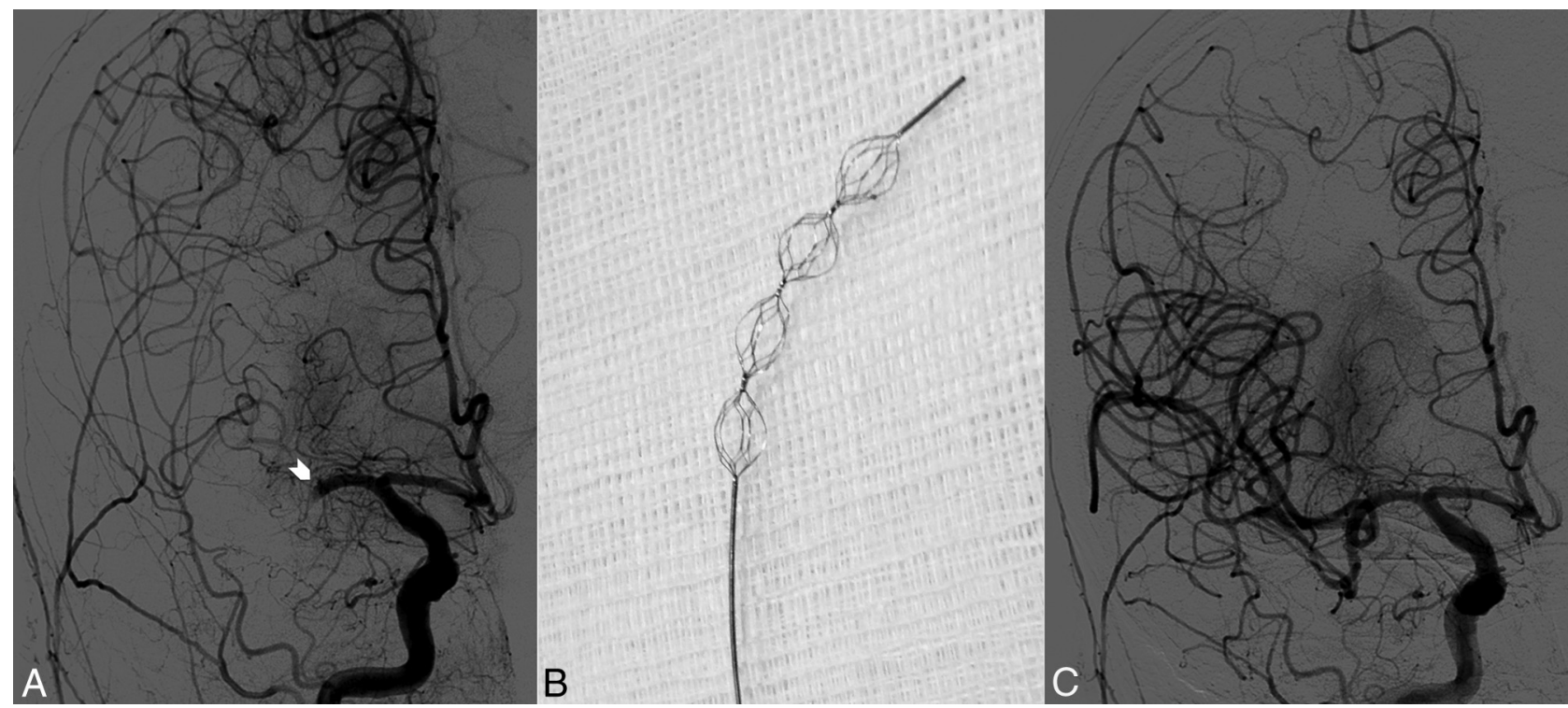

FIG 1. A, MCA M1 occlusion (white arrowhead). B, ERIC retriever tip. C, MCA M1 recanalized.

Table 1: Baseline characteristics of treated patients

\begin{tabular}{lc}
\multicolumn{1}{c}{ Characteristics } \\
\hline Age (mean) (yr) & $70 \pm 13$ \\
Female sex (\%) & 47.2 \\
Hypertension (\%) & 69.4 \\
Diabetes (\%) & 13.9 \\
Hypercholesterolemia (\%) & 44.4 \\
Smoking (\%) & 24.5 \\
Prior TIA/stroke (\%) & 8.3 \\
Modified Charlson Index (median) (IQR) & $1(0-2)$ \\
Prior PI/OAC (\%) & 47.2 \\
Baseline NIHSS (median) (IQR) & $18(10-20)$ \\
Intravenous thrombolysis (\%) & 55.5 \\
Site of vessel occlusion (\%) & \\
MCA-M1 & 52.8 \\
MCA-M2 & 25.0 \\
ICA-T & 11.1 \\
Other & 11.1 \\
& $n=36$ \\
\hline
\end{tabular}

Note:-PI indicates platelet inhibitor; OAC, oral anticoagulant; ICA-T, intracranial internal carotid artery bifurcation.

lowing criteria: 18 years of age or older; onset-to treatment time of $\leq 4.5$ hours or wake-up-stroke with relevant CT perfusion mismatch, NIHSS score of $\geq 4$, and proof of large-vessel occlusion in anterior circulation arteries (ICA, MCA, anterior cerebral artery) on CT angiography. As mentioned above, patients with unknown onset of symptoms (wake-up stroke) underwent a CTP series, which included a time-to-peak map with a threshold of $\geq 6$ seconds and a cerebral blood volume map. A TTP/CBV area ratio of $\geq 2$ was considered a relevant CTP mismatch.

IVT with $0.9 \mathrm{mg} / \mathrm{kg}$ of body weight was started immediately in eligible patients in-house or at the referring hospital if applicable. Intra-arterial urokinase (1.000.000 IU/60 minutes) was used in certain cases at the treating physician's discretion $(n=2)$.

We determined baseline characteristics, including age, sex, comorbidities, cardiovascular risk factors, previous medication, stroke severity, and site of vessel occlusion (Table 1).

\section{Outcome Measures}

We assessed treatment-related parameters such as onset-to-treatment time (last seen normal to groin puncture), procedural time (groin puncture to final recanalization), recanalization grade (Thrombolysis in Cerebral Infarction score), intra-/postprocedural complications (eg, symptomatic intracerebral hemorrhage $[\mathrm{sICH}])$, and functional outcome at discharge (NIHSS/mRS) and at 3 months (mRS).

Recanalization was defined as being "satisfactory" with TICI 2-3 and "excellent" with TICI 2b/3. Intraprocedural complications included vessel dissection or perforation, embolic events in previously unaffected territories, or sICH during the procedure. ${ }^{10}$ Intraprocedural symptomatic intracerebral hemorrhage was defined as proof of intracerebral hemorrhage on final tomography in the angiography suite and a decline in the NIHSS score of $\geq 4$ points. Functional outcome at 3 months was considered "favorable" with an $\mathrm{mRS}$ of $\leq 2$ (independent) and "satisfactory" with an $\mathrm{mRS}$ of $\leq 3$ (ambulatory without help).

\section{Endovascular Procedure}

The new ERIC is formed by 3-5 interlinked cages with diameters ranging from 3 to $6 \mathrm{~mm}$ and a resulting working length of 15-44 mm (Fig 1). Thus, the number of working cages can be adjusted to the required working length. The ERIC is designed to retract the clot coaxially and prevent the captured clot from shearing off during retraction. All procedures were performed on an Allura Xper FD20/20 biplane angiography system (Philips Healthcare, Best, the Netherlands) according to the departmental protocol with intraprocedural modification if required. Briefly, an $8 \mathrm{~F}$ balloon-guide catheter was placed in the distal common carotid artery. A heparinized saline solution was continuously perfused through the catheter during the procedure. With the balloon of the guide catheter deflated, a 0.0014 -inch guidewire was advanced coaxially over a Headway 17 Advanced Microcatheter (MicroVention) within the occluded intracranial vessel and navigated distal to the clot. The Headway 17 microcatheter was then advanced over the wire 
through the clot and the guidewire was exchanged for the embolectomy device. The ERIC was advanced and deployed a few millimeters distal to the clot. The balloon of the guide catheter was inflated, and the microcatheter and the embolectomy device were gently withdrawn under continuous proximal aspiration with a syringe. A control angiography was performed to confirm recanalization and reperfusion. Modifications of the standard procedure are reported in On-line Table 1.

\section{RESULTS}

\section{Baseline Data}

Patient baseline characteristics are presented in detail in Table 1. The mean age was $70 \pm 13$ years, and $47.2 \%$ were female patients. The median NIHSS score on admission was 18 (interquartile range [IQR], 10-20). Twenty-five patients had hypertension, 16 had hypercholesterolemia, and 5 had diabetes mellitus, and 9 were active cigarette smokers. In addition, the modified Charlson Index as a measure of comorbidities showed a light-to-moderate burden with a median modified Charlson Index of 1 (IQR, 0-2). Strokes of 36 patients were considered wake-up with undetermined onset of symptoms.

\section{Procedural Data}

CT angiography on admission revealed the following occlusion types: MCA M1 segment ( $n=19)$, MCA M2 segment $(n=9)$, terminal carotid-T $(n=4)$, tandem (intracranial internal carotid artery bifurcation-MCA, $n=3)$, and combined MCA M1 and anterior cerebral artery $(n=1)$ (Table 1$)$.

In 20 patients, intravenous tPA was started before mechanical thrombectomy. Intra-arterial urokinase was administered in another 2 patients without prior intravenous thrombolytic therapy. ERIC was used as the single retriever in 28 patients $(77.8 \%)$ and as a rescue device in 8 . Excellent recanalization was achieved in 30 of 36 patients $(83.3 \%$ ) with TICI 3 in 19/36 and 2 b in 11/36, respectively. Median procedural time was 90 minutes (IQR, 58-133 minutes) in these patients. General anesthesia was required in $13 / 36$ patients, whereas $23 / 36$ procedures were performed with the patient under conscious sedation. No intraprocedural switch from conscious sedation to general anesthesia was necessary, and no intraprocedural complications occurred. The median time from symptom onset to groin puncture was 4 hours 57 minutes (IQR, 3 hours 36 minutes to 7 hours 47 minutes).

\section{Clinical Outcome}

The median NIHSS score at discharge was 9 (IQR, 2-16), corresponding to a decrease of 9 points compared with the median NIHSS score on admission (Table 2). One-third of patients achieved favorable outcome ( $\mathrm{mRS} \leq 2)$ at 90 days after the ischemic event. Satisfactory outcome (mRS $\leq 3$ ) was achieved in $14 / 36$ when leaving the hospital, with an increase to $21 / 36(58 \%)$ 3 months later.

Three sICHs $(8.3 \%)$ were documented in the early course of hospitalization, all in patients with successful recanalization. No intraprocedural intracerebral hemorrhage occurred.

There was a $19.4 \%$ in-hospital mortality $(7 / 36)$ due to the development of fulminant cerebral edema despite successful recanalization in 3 patients (all TICI 3), followed by decompressive surgery in 2 of them and sICH in 1 of the latter. A fourth patient had vessel reocclusion on the same day after incomplete recanalization (TICI 2a) and developed a large MCA infarct. Because of considerable pre-stroke comorbidities with metastatic lung cancer and multiple myeloma, the latter patient's relatives and the treating physicians agreed to not extend diagnostic and therapeutic procedures according to the patient's presumed decision, with death on day 3. Accordingly, 3 patients with severe systemic infections (pneumonia in 2 and unidentified focus in 1) during hospitalization were continued on palliative care due to severe neurologic deficits, advanced age, and the poor prognosis. No intraprocedural deaths occurred.

During the 3-month follow-up, mortality further increased to $27.8 \%(10 / 36)$. One patient died 54 days after stroke during rehabilitation, with bacterial pneumonia and septicemia resulting in multiorgan failure. In the other 2 patients, therapeutic procedures were terminated in agreement with the patient's relatives and the patient's presumed decision due to age, stroke severity, and fatal prognosis.

One patient (patient 29, On-line Table 1) with successful recanalization and considerable clinical benefit, with an improvement from NIHSS 19 on admission to NIHSS 2 (and mRS 3) at discharge, underwent aortic arch replacement due to an incidental aortic arch aneurysm 10 weeks later. Perioperatively, he developed new focal neurologic deficits with proof of new ischemic infarcts on cranial CT, resulting in an mRS score of 5 at 3-month follow-up.

\section{DISCUSSION}

Retrieving thrombi with the new ERIC device was technically feasible, effective, and safe in this pilot study of acute ischemic stroke with large-vessel occlusion in anterior circulation arteries. The ERIC is designed to adapt to different vessel diameters and thrombus lengths and is thus available in diameters ranging from 3 to 6 $\mathrm{mm}$ and a working length of $15-44 \mathrm{~mm}$ with 3-5 spheres. The minimal required microcatheter internal diameter is 0.017 inches for all ERIC types. Proximal vessel occlusions, such as carotid-T occlusions, could be reached as easily as M2 branch occlusions in this pilot study.

Satisfactory recanalization with TICI grades 2-3 was demonstrated in $94.4 \%$, being excellent in $83.3 \%$ (TICI 2b-3). Additional thrombus aspiration at the end of the procedure further enhanced recanalization efficacy in 1 patient (patient 8). These high rates of successful recanalization also resulted in a substantial proportion of patients with an independent outcome ( $\mathrm{mRS} \leq 2$, $33.3 \%$ ). Of note, as many as 21 patients were ambulatory without help (mRS $\leq 3,58.3 \%) 3$ months after the index event. These findings are in line with the recently published Multicenter Randomized Clinical Trial of Endovascular Treatment for Acute Ischemic Stroke in the Netherlands (MR CLEAN) trail, ${ }^{11}$ predominantly using the Solitaire stent retriever (Covidien, Irvine, California) (mRS 2, 33\%; mRS 3, 51\%), and they are close to the results of the Spanish multicenter Endovascular Revascularization with Solitaire Device versus Best Medical Therapy in Anterior Circulation Stroke within 8 Hours (REVASCAT) trial ${ }^{12}$ (mRS 2, $44 \%$; mRS 3, 62\%). The higher rates of favorable functional outcome in the Endovascular Treatment for Small Core and Anterior 
Table 2: Procedural and outcome characteristics of treated patients

\begin{tabular}{lc}
\hline \multicolumn{1}{c}{ Characteristics } \\
\hline LSN to GP (median) (IQR) & $4 \mathrm{hr} 57$ min (3 hr 36 min to 7 hr $47 \mathrm{~min})$ \\
Procedural time (TICl 2b/3) & $90 \mathrm{~min}(58-133 \mathrm{~min})$ \\
(median) (IQR) & \\
Postprocedural TICI (\%) & 83.3 \\
2b/3 & 11.1 \\
2a & 5.5 \\
1 & $9(2-16)$ \\
NIHSS at discharge (median) & \\
(IQR) & \\
mRS at discharge (\%) & 27.8 \\
$0-2$ & 38.9 \\
$0-3$ & 19.4 \\
6 & \\
$\mathrm{mRS}$ at 3 mo (\%) & 33.3 \\
$0-2$ & 58.3 \\
$0-3$ & 27.8 \\
6 & 8.3 \\
sICH (\%)
\end{tabular}

Note:- LSN to GP indicates time from last seen normal to groin puncture.

Circulation Proximal Occlusion with Emphasis on Minimizing CT to Recanalization Times (ESCAPE) trial, ${ }^{13}$ Extending the Time for Thrombolysis in Emergency Neurological Deficits-Intra-Arterial (EXTEND-IA) trial, ${ }^{14}$ and Solitaire With the Intention For Thrombectomy as PRIMary Endovascular Treatment (SWIFT PRIME) trial ${ }^{15}$ are most likely attributable to a shorter time from stroke onset to mechanical thrombectomy (difference median, $>60$ minutes).

Overall, the median NIHSS score decreased from 18 points on admission to 9 points at discharge. The median NIHSS score on admission was 20 (range, 16-27) in patients who died during the 3-month follow-up period compared with 15 points (range, 5-21) in survivors. A high NIHSS score on admission is a known predictor of poor outcome, ${ }^{16}$ and despite the small numbers currently studied, our data further support this finding. Less than one-third of patients (10/36) died before the end of the 3-month follow-up period. None of those deaths could be directly attributed to the endovascular procedure or the retrieval device. The fulminant development of cerebral edema with or without sICH during hospitalization and the consequences of stroke severity and advanced age during follow-up explained the reported deaths. Moreover, the mortality rate was in line with previously published data of mechanical thrombectomy studies by using the Merci retriever (Concentric Medical, Mountain View, California), Penumbra System (Penumbra, Alameda, California), Revive device (Codman Neurovascular, Raynham, Massachusetts), or Trevo device (Stryker, Kalamazoo, Michigan), and it tended to slightly exceed mortality rates reported in many trials using the Solitaire stent retriever (compare On-line Table 2). However, until recently, these trials lacked power and were not designed to show the superiority of one device or the other. In particular, the study designs were very heterogeneous among those trials; small numbers were studied in most of the trials; and regarding the present observational single-arm study, more than onethird of the patients were treated in an extended time window, even beyond 6 hours from symptom onset based on CT mismatch.

In fact, given the promising results in terms of favorable and satisfactory outcome with the new ERIC retrieval device (mRS $\leq 2,33.3 \%$; $\mathrm{mRS} \leq 3,58.3 \%$ at 90 days), even in the light of a comparatively longer onset-to-treatment time by using advanced imaging protocols, the new ERIC adds a great asset to the existing armamentarium of recanalization devices. In addition, it further encourages research dealing with the use of advanced imaging techniques for patient selection.

Also in terms of safety, the ERIC appeared to be reliable and was free of intraprocedural complications. The rate of $\mathrm{sICH}$ $(8.3 \%)$ during hospitalization was comparable with that in previously reported trials using mechanical thrombectomy devices (On-line Table 2). Most interesting, all 3 sICHs in our pilot study occurred after the intervention and were associated with intravenous thrombolysis, successful recanalization, massive edema formation, and the need for decompressive surgery, indicating a common mechanism with underlying blood-brain barrier disruption.

Conscious sedation was chosen if possible. General anesthesia was required in 13/36 patients due to persisting vomiting, agitation, or impaired consciousness. However, the best anesthesiology management in endovascular stroke therapy is not known to date and is being investigated in a large randomized controlled trial (https://www.clinicaltrials.gov/; Sedation vs. Intubation for Endovascular Stroke TreAtment [SIESTA], NCT 02126085).

Our pilot study certainly has some limitations: the retrospective monocenter single-arm design, a rather small number of patients, and the lack of formally independent assessment of TICI score and procedural complications. Thus, the results should be interpreted with caution.

However, to our knowledge, this is the first report on consecutive patients with stroke treated with the new ERIC retrieval device. Our findings support the safety and effectiveness of mechanical thrombectomy in terms of vessel recanalization and show a clinical benefit. Moreover, despite the rather extended period from stroke onset to intervention and the lower rate of IVT, our results are promising and in line with previously published data by using other recanalization devices with a shorter time to treatment and higher rates of IVT.

After the stunning results of the Interventional Management of Stroke (IMS) III trial, SYNTHESIS expansion, and Mechanical Retrieval and Recanalization of Stroke Clots Using Embolectomy (MR RESCUE) trials, ${ }^{17-19}$ showing no benefit of endovascular treatment compared with standard care including IVT, the news from the latest trials, ie, MR CLEAN, ${ }^{11}$ ESCAPE, ${ }^{13}$ EXTENDIA,${ }^{14}$ SWIFT PRIME, ${ }^{15}$ and REVASCAT, ${ }^{12}$ clearly demonstrated the safety and effectiveness of an intra-arterial approach for acute stroke treatment in selected patients within the first hours of symptom onset.

\section{CONCLUSIONS}

The new ERIC retrieval device appears to be technically safe and effective in removing thrombi in large-vessel occlusion. Moreover, despite substantial focal neurologic deficits on admission and an onset-to-treatment time of, on average, $>6$ hours (mean, 6 hours 13 minutes; median, 4 hours 57 minutes), almost onethird of patients achieved an independent functional outcome 
and almost $60 \%$ were ambulatory without help 90 days after the ischemic event.

\section{ACKNOWLEDGMENTS}

We appreciate the professional cooperation of physicians, nurses, and technical assistants from the Departments of Anesthesiology, Neuroradiology, and Neurology in the specialized treatment of our patients with stroke.

Disclosures: Michael Diepers—UNRELATED: Consultancy: TETEC AG, Reutlingen, Comments: no connections to stroke therapies. Krassen Nedeltchev-UNRELATED: Board Membership: Advisory Boards: Bayer (Schweiz) AG, Boehringer Ingelheim (Schweiz) GmbH, Bristol Myers Squibb, Pfizer, AstraZeneca AG, GlaxoSmithKline, St. Jude Medical, Lundbeck (Schweiz) AG, Medtronic (Schweiz) AG, Sanofi-Aventis (Schweiz) AG, Genzyme, Shire, Biogen-Idec, Merck Serono, Teva Pharmaceutical Industries Ltd, Novartis Pharmaceuticals; Grants/Grants Pending: Swiss National Research Foundation, Swiss Heart Foundation, Research Council of the Cantonal Hospital of Aarau, Comments: grants outside the scope of the present work; Payment for Lectures (including service on Speakers Bureaus): Speakers Bureaus: Boehringer Ingelheim (Schweiz) GmbH, Bristol Myers Squibb, Pfizer, AstraZeneca AG, St. Jude Medical, Teva Pharmaceutical Industries Ltd.

\section{REFERENCES}

1. Rha JH, Saver JL. The impact of recanalization on ischemic stroke outcome: a meta-analysis. Stroke 2007;38:967-73 CrossRef Medline

2. The Neurological Disorers and Stroke rt-PA Stroke Study Group. Tissue plasminogen activator for acute ischemic stroke: Neurological Disorders and Stroke rt-PA Stroke Study Group. N Engl J Med 1995;333:1581-87 CrossRef Medline

3. Hacke W, Kaste M, Bluhmki E, et al; ECASS Investigators. Thrombolysis with alteplase 3 to $\mathbf{4} .5$ hours after acute ischemic stroke. N Engl J Med 2008;359:1317-29 CrossRef Medline

4. Saqqur M, Uchino K, Demchuk AM, et al; CLOTBUST Investigators. Site of arterial occlusion identified by transcranial Doppler predicts the response to intravenous thrombolysis for stroke. Stroke 2007;38:948-54 CrossRef Medline

5. Jansen O, Rohr A. Neurothrombectomy in the treatment of acute ischaemic stroke. Nat Rev Neurol 2013;9:645-52 CrossRef Medline

6. Spiotta AM, Chaudry MI, Hui FK, et al. Evolution of thrombectomy approaches and devices for acute stroke: a technical review. J Neurointerv Surg 2015;7:2-7 CrossRef Medline

7. Ribo M, Molina CA, Jankowitz B, et al. Stentrievers versus other endovascular treatment methods for acute stroke: comparison of procedural results and their relationship to outcomes. JNeurointerv Surg 2014;6:265-69 CrossRef Medline

8. Nogueira RG, Lutsep HL, Gupta R, et al; TREVO 2 Trialists. Trevo versus Merci retrievers for thrombectomy revascularisation of large vessel occlusions in acute ischaemic stroke (TREVO 2): a randomised trial. Lancet 2012;380:1231-40 CrossRef Medline

9. Saver JL, Jahan R, Levy EI, et al; SWIFT Trialists. Solitaire flow restoration device versus the Merci retriever in patients with acute ischaemic stroke (SWIFT): a randomised, parallel-group, non-inferiority trial. Lancet 2012;380:1241-49 CrossRef Medline

10. Nedeltchev K, Pattynama PM, Biaminoo G, et al; DEFINE Group. Standardized definitions and clinical endpoints in carotid artery and supra-aortic trunk revascularization trials. Catheter Cardiovasc Interv 2010;76:333-44 CrossRef Medline

11. Berkhemer OA, Fransen PS, Beumer D, et al. A randomized trial of intraarterial treatment for acute ischemic stroke. N Engl J Med 2015; 372:11-20 CrossRef Medline

12. Jovin TG, Chamorro A, Cobo E, et al; REVASCAT Trial Investigators. Thrombectomy within $\mathbf{8}$ hours after symptom onset in ischemic stroke. N Engl J Med 2015;372:2296-306 CrossRef Medline

13. Goyal M, Demchuk AM, Menon BK, et al; ESCAPE Trial Investigators. Randomized assessment of rapid endovascular treatment of ischemic stroke. N Engl J Med 2015;372:1019-30 CrossRef Medline

14. Campbell BC, Mitchell PJ, Kleinig TJ, et al; EXTEND-IA Investiga- tors. Endovascular therapy for ischemic stroke with perfusion-imaging selection. $N$ Engl J Med 2015;372:1009-18 CrossRef Medline

15. Saver JL, Goyal M, Bonafe A, et al; SWIFT PRIME Investigators. Stent-retriever thrombectomy after intravenous t-PA vs. t-PA alone in stroke. $N$ Engl J Med 2015;372:2285-95 CrossRef Medline

16. Adams HP Jr, Davis PH, Leira EC, et al. Baseline NIH Stroke Scale score strongly predicts outcome after stroke: a report of the Trial of Org 10172 in Acute Stroke Treatment (TOAST). Neurology 1999;53: 126-31 CrossRef Medline

17. Broderick JP, Palesch YY, Demchuk AM, et al; Interventional Management of Stroke (IMS) III Investigators. Endovascular therapy after intravenous t-PA versus t-PA alone for stroke. $N \mathrm{Engl} \mathrm{J} \mathrm{Med}$ 2013;368:893-903 CrossRef Medline

18. Ciccone A, Valvassori L, Nichelatti M, et al; SYNTHESIS Expansion Investigators. Endovascular treatment for acute ischemic stroke. N Engl J Med 2013;368:904-13 CrossRef Medline

19. Kidwell CS, Jahan R, Gornbein J, et al; MR RESCUE Investigators. A trial of imaging selection and endovascular treatment for ischemic stroke. N Engl J Med 2013;368:914-23 CrossRef Medline

20. Wardlaw JM, Murray V, Berge E, et al. Recombinant tissue plasminogen activator for acute ischaemic stroke: an updated systematic review and meta-analysis. Lancet 2012;379:2364-72 CrossRef Medline

21. Furlan A, Higashida R, Wechsler L, et al. Intra-arterial prourokinase for acute ischemic stroke: the PROACT II study: a randomized controlled trial-Prolyse in Acute Cerebral Thromboembolism. JAMA 1999;282:2003-11 CrossRef Medline

22. Ogawa A, Mori E, Minematsu K, et al; MELT Japan Study Group. Randomized trial of intraarterial infusion of urokinase within 6 hours of middle cerebral artery stroke: the middle cerebral artery embolism local fibrinolytic intervention trial (MELT) Japan. Stroke 2007;38:2633-39 CrossRef Medline

23. IMS Study Investigators. Combined intravenous and intra-arterial recanalization for acute ischemic stroke: the Interventional Management of Stroke Study. Stroke 2004;35:904-11 CrossRef Medline

24. IMS II Trial Investigators. The Interventional Management of Stroke (IMS) II Study. Stroke 2007;38:2127-35 CrossRef Medline

25. Mazighi M, Serfaty JM, Labreuche J, et al; RECANALISE investigators. Comparison of intravenous alteplase with a combined intravenous-endovascular approach in patients with stroke and confirmed arterial occlusion (RECANALISE study): a prospective cohort study. Lancet Neurol 2009;8:802-09 CrossRef Medline

26. Smith WS, Sung G, Starkman S, et al; MERCI Trial Investigators. Safety and efficacy of mechanical embolectomy in acute ischemic stroke: results of the MERCI trial. Stroke 2005;36:1432-38 CrossRef Medline

27. Smith WS, Sung G, Saver J, et al. Mechanical thrombectomy for acute ischemic stroke: final results of the Multi MERCI trial. Stroke 2008;39:1205-12 CrossRef Medline

28. Penumbra Pivotal Stroke Trial Investigators. The Penumbra pivotal stroke trial: safety and effectiveness of a new generation of mechanical devices for clot removal in intracranial large vessel occlusive disease. Stroke 2009;40:2761-68 CrossRef Medline

29. Menon BK, Hill MD, Eesa M, et al. Initial experience with the Penumbra stroke system for recanalization of large vessel occlusions in acute ischemic stroke. Neuroradiology 2011;53:261-66 CrossRef Medline

30. Castaño C, Dorado L, Guerrero C, et al. Mechanical thrombectomy with the Solitaire AB device in large artery occlusions of the anterior circulation: a pilot study. Stroke 2010;41:1836-40 CrossRef Medline

31. Roth C, Papanagiotou P, Behnke S, et al. Stent-assisted mechanical recanalization for treatment of acute intracerebral artery occlusions. Stroke 2010;41:2559-67 CrossRef Medline

32. Miteff F, Faulder KC, Goh AC, et al. Mechanical thrombectomy with a self-expanding retrievable intracranial stent (Solitaire $A B$ ): experience in 26 patients with acute cerebral artery occlusion. AJNR Am J Neuroradiol 2011;32:1078-81 CrossRef Medline 
33. Wehrschuetz M, Wehrschuetz E, Augustin M, et al. Early single center experience with the Solitaire thrombectomy device for the treatment of acute ischemic stroke. Interv Neuroradiol 2011;17:235-40 Medline

34. Dorn F, Stehle S, Lockau H, et al. Endovascular treatment of acute intracerebral artery occlusions with the Solitaire stent: single-centre experience with 108 recanalization procedures. Cerebrovasc Dis 2012;34:70-77 CrossRef Medline

35. Pereira VM, Gralla J, Davalos A, et al. Prospective, multicenter, single-arm study of mechanical thrombectomy using Solitaire Flow Restoration in acute ischemic stroke. Stroke 2013;44:2802-07 CrossRef Medline

36. San Román L, Obach V, Blasco J, et al. Single-center experience of cerebral artery thrombectomy using the TREVO device in $60 \mathrm{pa}-$ tients with acute ischemic stroke. Stroke 2012;43:1657-59 CrossRef Medline

37. Mendonça N, Flores A, Pagola J, et al. Trevo system: single-center experience with a novel mechanical thrombectomy device. J Neuroimaging 2013;23:7-11 CrossRef Medline

38. Rohde S, Haehnel S, Herweh C, et al. Mechanical thrombectomy in acute embolic stroke: preliminary results with the Revive device. Stroke 2011;42:2954-56 CrossRef Medline

39. Kurre W, Aguilar-Pérez M, Schmid E, et al. Clinical experience with the pREset stent retriever for the treatment of acute ischemic stroke: a review of 271 consecutive cases. Neuroradiology 2014;56: 397-403 CrossRef Medline 